\title{
ESPAÇO DE PROJEÇÃO DO PATRIMÔNIO ARTÍSTICO E CULTURAL GUARANI MBYÁ
}

Cristina R. Campos

Sujeitos/objetos da cultura material e imaterial, textos, fotografias, instalações cenográficas, jogos interativos, elementos audiovisuais da produção artística guarani mbyá se apresentam num espaço de projeção penetrável, econômico, simbólico, através da interpenetração de desejos e modos de vida. [Abstract on page 243]

\section{GUARANI MBYÁ, ARTE/CULTURA, MUSEU, PATRIMÔNIO.}


A permanente dinâmica de descobrir o outro, a atração exercida pelo diferente, pelo exótico produziu histórias. De curiosidades, os objetos trocados, pilhados se transformaram nas chamadas coleções etnográficas armazenadas e exibidas em grandes museus por todo o mundo. Da segunda metade do século XVIII até finais do XIX, viajantes e naturalistas estiveram nas Américas recolhendo objetos de história natural, objetos artesanais, vestígios de culturas fadadas ao desaparecimento, objetos que expressavam a origem e evolução do homem, os conduzindo à Europa e depositando em instituições públicas. No contexto de uma ciência marcadamente positivista, os museus de história natural abrigavam grande acervo cujo principal objetivo é a guarda de provas documentais sobre a natureza - vegetal, animal ou humana.

As coleções de costumes tradicionais formam a base das primeiras mostras etnográficas, tal como apareceram nas exposições universais. Anne-Marie Tiesse argumenta que desde a primeira delas, inaugurada em Londres em 1851, além de mostrarem as inovações tecnológicas e industriais, são também exibições identitárias por meio das quais cada nação valoriza seu patrimônio ancestral, com intuito de estimular os sentimentos patrióticos dos visitantes. "A relação entre o político e o cultural permanece como um dos pontos cruciais da reflexão sobre o nacional, inclusive na perspectiva de sua superação no global" (TIESSE, s.d.: 23).

No Brasil, os primeiros grandes museus fundados sob a perspectiva evolucionista e naturalista, com prática de colecionamento de vestígios de outros povos ligada à antropologia física, foram o Museu Nacional (1818) no Rio de Janeiro, o Museu Paraense Emílio Goeldi (1866) em Belém e o Museu Paulista (1894) em São Paulo.

Com a emergência da antropologia social ou cultural, as sociedades não ocidentais passaram a ser ordenadas por uma nova categoria-chave, a de cultura, sendo então relevante o estudo das diferenças culturais entre os homens, e o principal dispositivo para conhecê-las passou a ser a pesquisa de campo. A perspectiva relativista punha em marcha novos estudos sobre o outro. Regina Abreu salienta que:

experimentar o lugar do outro se provou condição para expressar a diferença em seus próprios termos, ou seja, não apenas descrever diferentes culturas a partir da subjetividade própria do homem ocidental moderno, como também despir-se de todos os preconceitos para ir ao encontro de outras formas de subjetividade (ABREU, 2008: 41).

Esse momento da história da antropologia marcou o surgimento de museus etnográficos ou etnológicos, que se configuraram como espaço de difusão do conceito de cultura. O Museu do Homem, criado em Paris nos anos 40-50, concebido a partir da proposta de Georges-Henri Rivière e Paul Rivet, que tinha como finalidade apresentar a unidade do homem enriquecida por diferenças entre culturas, foi exemplo emblemático dessa concepção.

Nas primeiras décadas do século XX, culminou uma série de estudos em que predominava um olhar refinado para o modo de ser e viver dos nativos - coleta de artefatos, 
sistematização das línguas, descrição da organização social e dos sistemas cosmológicos dos rituais -, designados a demarcar e salvaguardar as singularidades de cada cultura.

No Brasil, essa proposta repercutiu em novas construções e ideais. Em 1979, Gilberto Freyre participou da criação do Museu do Homem do Nordeste, situado em Recife, que tem como missão pesquisar, documentar, preservar, difundir e atualizar o patrimônio cultural, material e imaterial do Nordeste. Darcy Ribeiro concretizou, em 1953, o projeto concebido na Seção de Estudos do Serviço de Proteção aos Índios, com vistas a criar espaço dedicado exclusivamente às culturas indígenas - o Museu do Índio. Órgão científico-cultural da Fundação Nacional do Índio (Funai), o museu instalou-se inicialmente no bairro do Maracanã, na cidade do Rio de Janeiro e, em 1978, mudou-se para o espaço atual, em Botafogo - um prédio do século XIX, construído por João Rodrigues Teixeira, empresário da indústria alimentícia do Rio de Janeiro, para sua residência. Tombado pelo Instituto do Patrimônio Histórico e Artístico Nacional (Iphan), a construção é exemplar arquitetônico representativo do período de urbanização do bairro.

Os museus se multiplicaram no Brasil e no mundo. Na década de 1980, uma nova "imaginação museal", conforme Mario Chagas (2009), resultou no surgimento de novas experiências: o ecomuseu aberto para conexões entre cultura e natureza, entre museu e meio ambiente e que, posteriormente, agregou noções de patrimônio total ou integral, participação comunitária, desenvolvimento local e territorial; o museu integrado ou integral, cuja proposta leva em consideração a totalidade dos problemas da sociedade, instrumento dinâmico de ação social. Os museus, que até então proclamavam sua neutralidade política, foram desafiados a operar com relações de memória e poder por mediação de coisas concretas que diziam respeito não apenas a tradições de um passado idealizado, mas também ao cotidiano das sociedades em que estavam inseridos.

O questionamento de parâmetros socialmente estabelecidos, iniciado na década de 1970, levou a sociedade a se organizar em diferentes movimentos sociais. Em 1990 e, principalmente, 2000 disseminam-se no Brasil organizações não governamentais (ONGs) voltadas para operacionalizar as demandas focadas em ações estratégicas, com captação de recurso junto ao Estado ou a entidades internacionais que, em sua maioria, surgiram como forma de operacionalizar a luta dos movimentos sociais desejosos de eternizar suas histórias e construir seus próprios lugares de memórias.

As sociedades estudadas por antropólogos começaram a se organizar e a valorizar suas práticas culturais - reivindicam para si um lugar ativo de sujeito, mobilizam-se contra a homogeneização e o etnocentrismo. Surgem em todo o mundo museus tribais e de comunidades. No Brasil, na categoria tribal, podemos citar o Museu Máguta, dos índios tikuna, na Amazônia, o Museu Koary, dos índios do Oiapoque, no Amapá; na categoria de museus de comunidade o Museu da Maré, no Rio de Janeiro.

Trata-se não mais de representações ou de construções de alteridade efetuadas exclusivamente numa relação de colecionamento do outro por naturalistas ou antropólogos, e sim de processos dialógicos em que representações e construções alteritárias se mesclam com autorrepresentações e processos de construção de identidade. Os "nati- 
vos", antes um objeto da ciência, afirmam-se hoje como sujeitos do processo de produção de conhecimento sobre si próprios (ABREU, 2008: 55-56).

O surgimento de centros culturais e de museus tribais torna possíveis o efetivo repatriamento e a circulação de objetos. Atualmente na Europa as novas propostas de museus substituíram o tema da diferença entre culturas por um

10 termo mônadas surgiu com Giordano Bruno, significando os elementos das coisas. Mais tarde, foi utilizado por Leibniz ([1714] 1991: 123) como partículas que podem trazer o sentido do todo. A alma humana é uma mônada, e Deus é ao mesmo tempo a mônada mínima e a máxima, porque tudo vem dele. Segundo Leibniz (123-125), a mônada é "substância simples" composta de um "aggregatum" das coisas simples. Elas não podem ser divididas, entendidas ou representadas por figuras. Elas "são os verdadeiros Átomos da Natureza e numa palavra os Elementos das coisas". olhar que privilegia a noção de diversidade cultural como mercadoria etnoturística, dando lugar ao entendimento das culturas como "mônadas identitárias", ${ }^{1}$ em que a "noção de diversidade cultural tenderia a se tornar absoluta em singularidades identitárias cristalizadas e formatadas para um mercado ávido pela construção de heterogeneidades decorrentes de uma homogeneização globalizadora" (ABREU, 2008: 56). O mundo tal como foi imaginado por Leibniz (1991) está cheio de mônadas criadas ou derivadas de Deus, considerado o Arquiteto da Máquina do Universo. Portanto, as mônadas identitárias constituem representação ideal do mundo de uma época passada. Partindo-se da hipótese das informações compreendidas como mônadas, pode-se concluir que há o risco de se construírem novas utopias - o mundo monadológico não faz parte do mundo material. Ele se integra ao domínio religioso e foge da realidade material que suporta as ideias atuais, porém alimenta as desejadas.

No que diz respeito à coleta, à preservação das práticas orais e artísticas indígenas, desde o século XIX, com o aparecimento da fotografia, do cinema e de tecnologias de reprodução, parte considerável da memória social tem sido estocada em imagens fixas e móveis. Leila Beatriz Ribeiro assinala que a mediação simbólica entre sujeito e visualidade não só está revestida de significados, saberes, narrativas e informações como também antecede a constituição das próprias práticas. O sujeito, ao buscar uma referência simbólica e cultural, acionaria de forma antropológica, uma relação de inserção com o coletivo.

Ao trabalhar com a visualidade, busca-se apreender essa questão no espaço da cultura, isto é, percebê-la como meio ou estratégia que possibilita referenciá-la sob as diversas linguagens que veicula, assim como entender as reinvenções dela advindas como construções híbridas (RIBEIRO, 2008:70).

O campo da antropologia da comunicação visual é significativo na verificação de algumas formas de subjetividades que são construídas e reconstruídas por meio da linguagem visual. Massimo Canevacci (2001) alerta sobre o papel fundamental da comunicação na transformação da sociedade. Hoje, o desafio é penetrar e fazer-se penetrar, olhar e fazer-se olhar, fazer-se ver - como contexto de pesquisa e laboratório de práticas em que corpos se embrenham, provocando a necessidade de elaborar novos sistemas perceptivos e novas sensorialidades aplicadas ao dinamismo contemporâneo. 
Nos dias atuais, o turismo, a revitalização dos museus e o comércio da arte, do artesanato, da música e de livros são as principais fontes que alimentam de maneira forte e explícita a presença e a continuidade da imagem das sociedades tradicionais como sinônimos de lugar misterioso, quintessência da conservação de valores e práticas tradicionais. Os impactos da globalização vão desenhando mudanças tanto de mentalidades, do imaginário como de práticas sociais, de suas formas de expressão, parece que diferentes sujeitos, notadamente aqueles que vivem nas fronteiras culturais, sonham com um desenvolvimento que permita sua circulação. O etnoturismo, a comercialização da arte/ cultura e as atividades de pesquisa de diferentes campos produzem trocas simbólicas e econômicas, e, através delas, trocas de experiências e interpenetração de desejos e modos de vida.

Tendo em mente esse cenário de patrimônio e evocação da memória guarani mbyá, apresento uma análise das representações artístico-culturais dessa etnia. Que "saberes" sobre eles estão sendo difundidos? Quem são os produtores? Para quem estão servindo as representações Mbyá?

\section{OS GUARANI MBYÁ NO MUSEU DO ÍNDIO²}

O Museu do Índio, em 2009, lançou o programa "Índio no Museu", que consiste no convite de uma etnia para participar da montagem e realização de uma exposição. A proposta se baseia na participação dos índios no processo de documentação de suas culturas com foco na cultura material e produção de bens, e na valorização do artesanato indígena, por meio de ações que contribuam para transformações nas relações de comércio com a sociedade brasileira, com alternativas adequadas de sustentabilidade econômica.

José Carlos Levinho, diretor do Museu do Índio, explica que o museu "é uma instituição que tem a obrigação de fornecer informações corretas e atualizadas sobre os índios e ao mesmo tempo cumprir o papel que lhe cabe: documentação de acervos audiovisuais, textuais e de peças etnográficas". Acredita que é neste contexto que um órgão governamental deve funcionar: documentar e difundir as culturas indígenas.

Os Guarani Mbyá do Estado do Rio fizeram parte dessa iniciativa intitulada "Índio no Museu: os Mbyá", que contou com apoio da Fundação Banco do Brasil e da Unesco. O evento integra os espaços expositivos da instituição: Espaço Museu das Aldeias, com a exposição etnográfica Tape Porã, impressões em movimento - os Mbyá no Rio de Janeiro; Espaço Muro do Museu, com a mostra fotográfica Ojapo Porã'i; Galeria de Arte Indígena, com a mostra de venda Ombopara. A exposição, com cerca de 60 peças, fotos e vídeos, procura refletir sobre o movimento/deslocamento na experiência de vida dos Mbyá, a qual se liga estreitamente à produção do
2 As informações aqui apresentadas foram retiradas do folder e do catálogo da exposição, assim como dos depoimentos colhidos em entrevistas realizadas, em dezembro de 2009 e janeiro de 2010, com o diretor do Museu do Índio, José Carlos Levinho, a design Simone Mello, o pesquisador Rafael Mendes Junior, os professores guarani Eloir Werá Xondaro e Arnildo Werá, que na ocasião estavam visitando seus parentes na Aldeia Tekoa Mbo'yty, e o escultor e cineasta Miguel Rogério Vera Mirim, dessa aldeia. Os depoimentos de Eloir, Arnildo e Miguel foram colhidos no próprio local da exposição, após sua apreciação. 


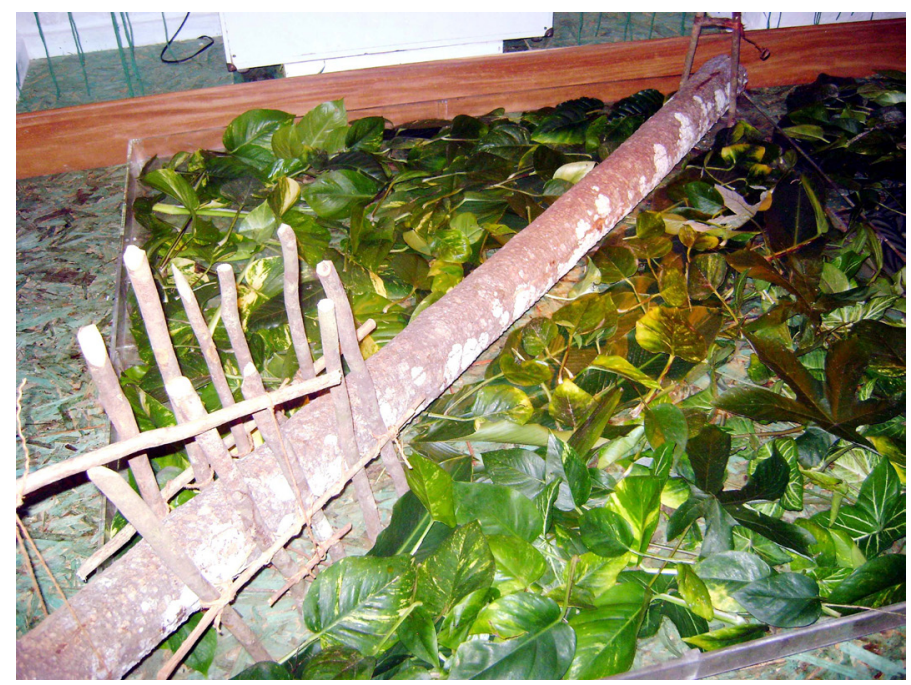

Figura 1:

Armadilha

Foto: Cristina

Campos, 2009

que eles chamam de "estar bem" (iko porã) e que significa tanto estar com saúde quanto estar "alegre" ( $\left.v y^{\prime} a\right)$. Os objetos exibidos carregam marcas da história desse povo.

A equipe do Museu Índio - museólogos, arquivistas, fotógrafos, educadores, design - contou também com a curadoria de Elizabeth Pissolato, a pesquisa de Rafael Fernandes Mendes Junior, ambos antropólogos, que realizaram suas pesquisas de campo nas aldeias Guarani Mbyá do Estado do Rio de Janeiro. A de Elizabeth Pissolato, que resultou no livro A duração da pessoa: mobilidade, parentesco e xamanismo mbyá (2007), tem a atenção voltada para a experiência individual das relações sociais entre os humanos ou entre os deuses; a de Rafael Mendes Junior versou sobre o tema Caça e comercialidade e resultou, por sua vez, em dissertação de mestrado defendida em 2009. Esses temas estão presentes e materializados na exposição.

Nos nove meses que precederam a exposição foram realizadas oficinas de fotografia e filmagem, oficina de trançado com papel reciclado, coleta, seleção e compra de objetos. Rafael Mendes Junior conta que a aquisição dos objetos se deu a partir da divulgação nas aldeias do interesse do Museu do Índio em comprar produtos artísticos guaranis, porém os mesmos deveriam ser "muito bem elaborados e confeccionados pelos melhores artesãos do local". Os próprios Guarani contatados indicavam os mais habilidosos na produção definida pelos organizadores para integrar a exposição - cestos, balaios, bichinhos, tapetes, armadilhas, cachimbos, colares, tornozeleiras, bancos. A escoIha dos objetos deu-se também a partir da pesquisa de campo, da observação em fotografias e filmes disponíveis nos arquivos dos pesquisadores e do museu. Sendo assim, foram mapeados os considerados "melhores artesãos". Rafael Mendes Junior ressalta que a exposição

é uma tentativa de descrever densamente como os Guarani representam o próprio espaço. É claro que a gente privilegia o mais importante e o menos 


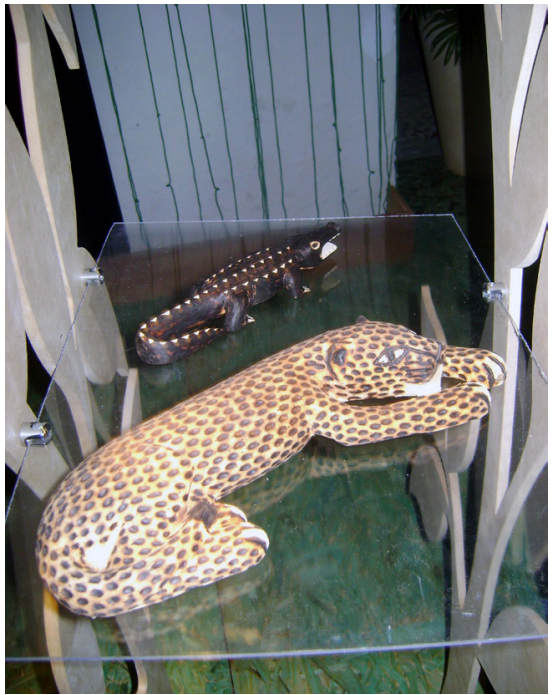

Figura 2: Animais envolvidos na folhagem Foto: Cristina Campos, 2009

importante. Após as informações que nos são dadas, que chegam de uma forma caótica, delimitamos um tema e construímos um discurso sobre o outro.

No momento da montagem da exposição a equipe optou por organizar o material segundo categorias: cestos coloridos, cestos com cores naturais, tramas e grafismos, cestos com acabamento arredondado, tapetes/painéis, objetos mais elabora-

dos (artísticos - em uma sala específica), objetos menos elaborados (comercial - no espaço destinado à venda), elementos da natureza e sobrenatureza. A autoria dos objetos expostos foi indicada somente no catálogo das peças. Rafael Mendes Junior argumenta que o quantitativo de peças organizado no mesmo local, bem como, a produção coletiva de alguns objetos, inviabilizou a identificação dos autores das obras.

Outro fator também percebido é o modo de exposição diferenciado do costumeiro guarani quando coloca suas peças à venda - o agrupamento é feito de acordo com os núcleos familiares que produziram os objetos. Esse é um modo que representa a organização social e cosmológica do grupo, uma organização que prima por seus núcleos familiares, sejam eles da ordem da natureza ou sobrenatureza. Dito de outro modo, segue o esquema da origem do povo Guarani: toda espécie era humana; num dado momento, de acordo com suas ações, foram (trans)formados, surgindo então, outros núcleos familiares (de plantas, animais, entre outros) que convivem no mesmo tempo e espaço, o Ara Ypy, circundados pelos espíritos. Os guarani estão em rede com os seres visíveis e invisíveis e com eles se relacionam.

Os objetos expostos foram comprados em sua maioria nas diversas aldeias guaranis localizadas no Estado do Rio de Janeiro, sendo alguns trazidos de aldeias de outros estados, por parentes, para negociação. Nesse cenário, os sujeitos/objetos se apresentaram distribuídos nos espaços expositivos que detalho a seguir.

\section{EXPOSIÇÃO ETNOGRÁFICA TAPE PORÃ, IMPRESSÕES EM MOVIMENTO - OS MBYÁ NO RIO DE JANEIRO, NO ESPAÇO MUSEU DAS ALDEIAS}

O "bom caminho", tradução do tema da exposição, de acordo com os idealizadores Elizabeth Pissolato e Rafael Mendes Junior, representa a diversidade de caminhos que 


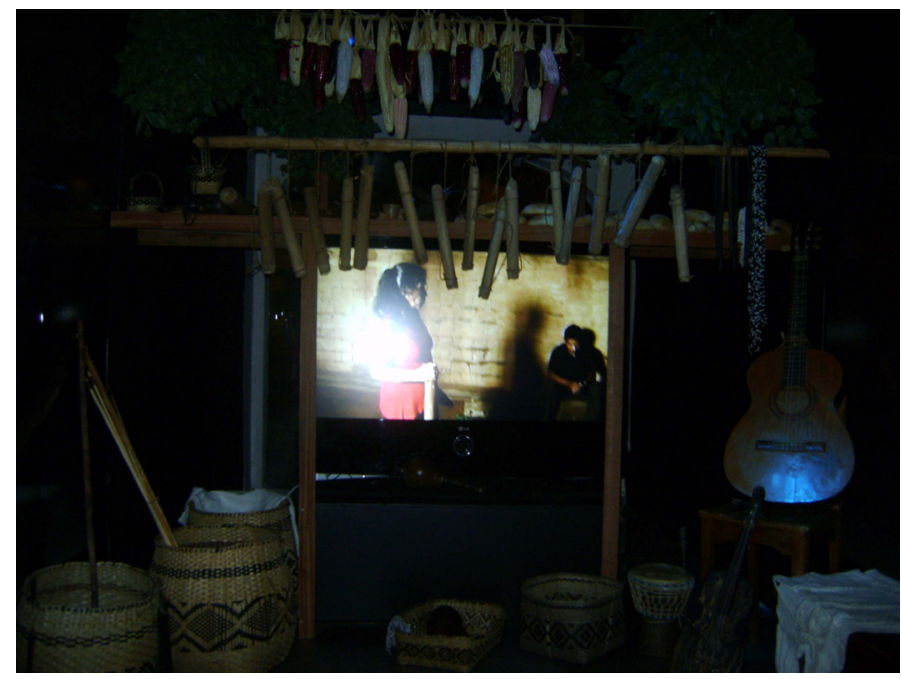

Figura 3:

Instalação

Ambai/TV.

Foto: Cristina

Campos, 2010

os Mbyá percorrem, seja pela mata em busca da caça, seja pela relação com a sobrenatureza, seja pela experimentação de novos ambientes, seja pela visita aos parentes em outras aldeias, seja pela estrada que liga a cidade, onde se dá a troca com os brancos, os não índios. Esse movimento horizontal, como todos os outros que fazem parte do modo de ser guarani, é orientado pelos deuses representados pelo pai primeiro Nhanderu. Sendo assim, a exposição pretende criar um espaço de experimentação desses movimentos, numa tentativa de descrever como os Guarani representam e se apresentam nesse tempo/espaço.

Na primeira sala o enfoque é a mata, lugar em que se sentem bem para morar espaço privilegiado para a caça. As armadilhas para a captura de animais, as imagens da mata e também do cotidiano transmitidas no vídeo, as esculturas de animais envolvidas por árvores estilizadas de madeira crua foram ambientadas num cenário composto por sons, cheiro da natureza e iluminação reduzida (figuras 1 e 2).

A designer Simone Mello, que compõe a equipe do Museu do Índio, declarou que seu objetivo era "levar a peça do contexto etnográfico para um ambiente cênico: envolver com luz, cheiro, produzir o contexto do ambiente".

A importância dos mais velhos para os Guarani é exibida numa instalação composta por uma TV e banquinhos ao redor - Espaço da Partilha. No vídeo, o café da manhã é apresentado como momento de partilha em que o mais velho, após ouvir as histórias dos mais novos, orienta o melhor caminho a seguir, caminho esse que possibilitará a alegria - sair pela mata, visitar um parente em outra aldeia, ir à cidade, procurar outro lugar para morar, entre outros desejos - simbolizando a ideia de movimento.

Passando para a segunda sala, o espaço converge para a vida cerimonial dos Mbyá, que acontece na Opy (Casa de Reza). No fundo da pequena sala, o vídeo projeta- 


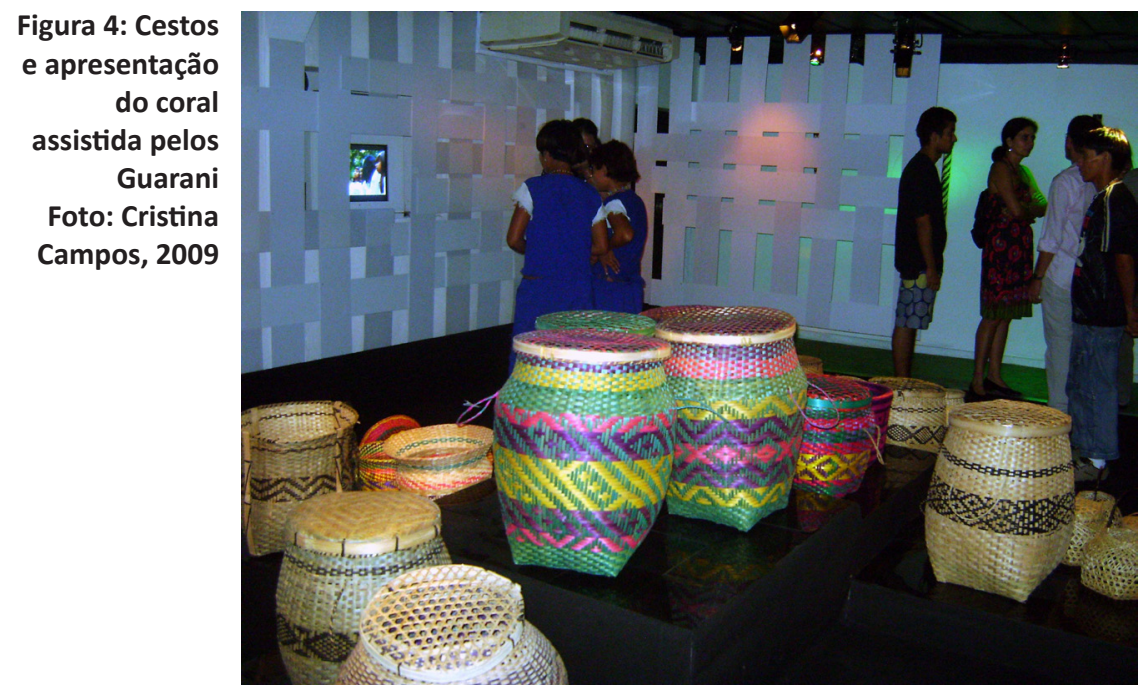

do, que exibe uma cura realizada pelo pajé Augustinho da Aldeia Araponga, é incorporado ao Ambai (instalação composta por sujeitos/objetos cerimoniais) (Figura 3).

Os nomes exibidos no teto revelam a crença guarani de que são enviados por Nhanderu - o pai das almas, que vive no espaço cósmico - e são traduzidos pelos idealizadores da exposição como "vindos de cima para baixo". Rafael Mendes Junior conta que os Guarani creem que as pessoas já nascem com um nome e no ritual Nimongarai o pajé o revela para a comunidade.

Eloir Werá Xondaro e Arnildo Werá ficaram estáticos ao ver a exibição de uma cura. Argumentaram que na aldeia em que vivem esse ritual não pode ser mostrado aos juruá (nome atribuído aos homens brancos, não índios). Na entrevista coletiva com Rafael Mendes Junior, falaram novamente sobre esse estranhamento. Ele explicou que a cura projetada foi uma demonstração de como se faz uma cura e que o pajé, senhor Augustinho, e sua esposa, dona Marciana, consideraram importante a revelação. No dia da filmagem, que durou 15 minutos, os protagonistas ambientaram o espaço, se prepararam e realizaram a encenação.

A terceira sala se constitui como um espaço da relação dos Guarani com os juruás, onde se dá a comercialização do artesanato e a apresentação dos corais. No centro da sala, os cestos mostram diferentes desenhos obtidos pelo trançado. Na parede o trançado feito com barras de pet (material de plástico branco leitoso) pelo grupo guarani que participou da montagem da exposição ganha amplitude e revela a transposição da concepção empregada na produção da cestaria - trama complexa geradora de superfícies intercambiáveis.

Em meio à trama criada na parede, a TV exibe apresentações do coral. Cabe dizer que os visitantes guaranis que na abertura da exposição se apresentaram elevando a palavra cantada se encantaram ao se sentir presentes na tela (Figura 4). 


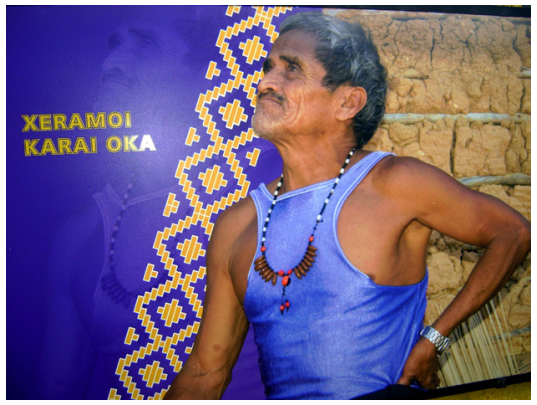

Figura 5: Xeramoi Karai Oka, o mais velho e sábio da aldeia (tradução: Eloir Wera Xondaro) Foto: Cristina Campos, 2010

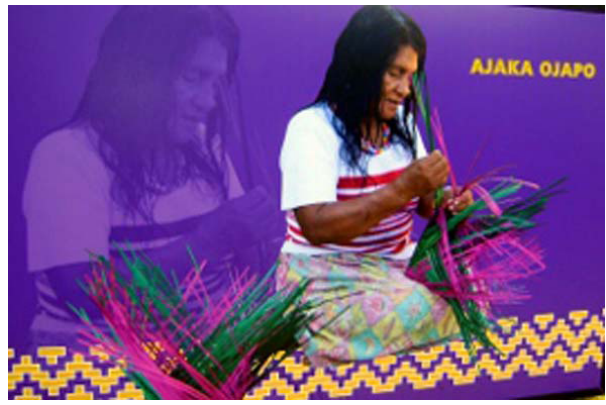

Figura 6: Ajaka Ojapo, fazendo cesto (tradução: Eloir Wera Xondaro). Foto: Cristina Campos, 2010

Exposição fotográfica Ojapo Porã'i (que significa fazer bonito ou bem fazer) no espaço Muro do Museu. São 20 fotos produzidas por moças e rapazes durante oficinas realizadas nas aldeias e organizadas pela equipe do Museu do Índio. As fotografias receberam posteriormente "tratamento" profissional adequado ao senso estético dos brancos - o fundo na cor roxa, as sombras e os textos integraram o sujeito/objeto exposto (figuras 5 e 6$)$.

As imagens/textos refletiram momentos do cotidiano escolhido para representar o sentido ético e estético dos Mbyá. No entanto, é importante ressaltar que esse sentido faz interface com o senso dos "promotores" da oficina - a imagem que combinaram mostrar. Segundo Levinho, "os Guarani não tiveram esse tipo de qualificação, não têm sofisticação para constituir uma linguagem com o material produzido; assim, foi necessária nossa intervenção, como no caso das fotos". Eu diria, em toda a exposição, pois os trabaIhos apresentados, ainda que com a participação dos índios, o foram em concepção museológica dos juruás.

Mostra de venda Ombopara (traduzido pelos Guarani como grafar, desenhar, enfeitar) na galeria. Os objetos expostos nessa sala foram organizados de acordo com as unidades de produção de determinada aldeia ou grupo. Na vitrina, painéis, cestos, esculturas, bancos estimulam os visitantes à aquisição da arte guarani (figuras 7,8 e 9).

No interior do espaço os produtos estão agrupados por semelhança de material e aparência. A apropriação do trançado no papel reciclado aguça olhares cuidadosos (Figura 10). As duas mil agendas foram produzidas sob encomenda da Eletrobras em oficina que durou quatro meses. Levinho salienta:

Foram duas mil agendas, todas diferentes uma da outra. Impressionante o que eles fizeram, surpreendente. Temos um produto fantástico na mão, muito bonito para oferecer ao público. Mas foi um esforço muito grande; procuramos respeitar a especificidade deles naquilo que fazem melhor, que é essa coisa do 

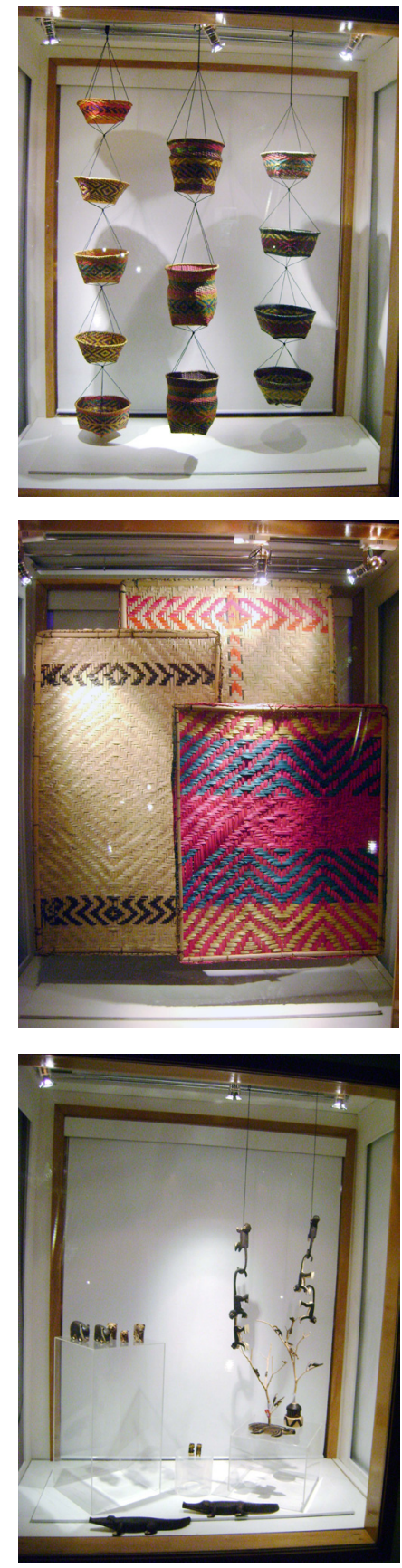

Figuras 7, 8 e 9: Objetos na vitrina

Fotos: Cristina Campos, 2009 trançado, e deu certo. Fizeram um trabalho de uma plasticidade, de uma beleza absurda!

O Museu do Índio, com esse projeto, pretende qualificar o artesanato, fornecer subsídios e informações para que as peças não sejam meros objetos, mas um trabalho artístico, um trabalho elaborado com valor integrado ao comercial. Ou, ainda, uma iniciativa para agregar conteúdo social, artístico e étnico às peças comercializadas, contextualizando a arte guarani no nicho de mercado ecológico, já que os objetos vendidos por eles no Rio de Janeiro são feitos de fibra de bambu. A renda obtida reverterá para as associações mbyá. A ideia do diretor do museu é criar um fundo de venda -a cada peça vendida, uma nova pode ser comprada, ou seja, viabiliza produção permanente de objetos. Outra iniciativa consiste nas bolsas de estudo oferecidas aos interessados no aprendizado da pesquisa e documentação de sua própria cultura. Levinho diz que os Guarani

estão sendo treinados para documentar a cultura deles, para ser pesquisadores de sua própria cultura. A ideia é formar um banco de dados a que eles tenham acesso e que possam constantemente alimentar o arquivo com novas informações, fazendo delas o que meIhor lhes convier. Acho que essa é a meIhor maneira de se falar em protagonismo indígena, em participação indígena. Tem que ter formação, tem que ter qualificação, fornecer as ferramentas e deixá-los administrarem e mostrar também os caminhos, porque não adianta fazer um feijão com arroz sem qualidade.

Como desdobramento da exposição outros produtos estão previstos: catálogo, site, postal. Pensam também em levá-la para outros espaços, buscando mais visibilidade e circularidade para a arte guarani.

A exposição no Museu do Índio, sob o olhar guarani, demanda algumas considerações. Os pro- 


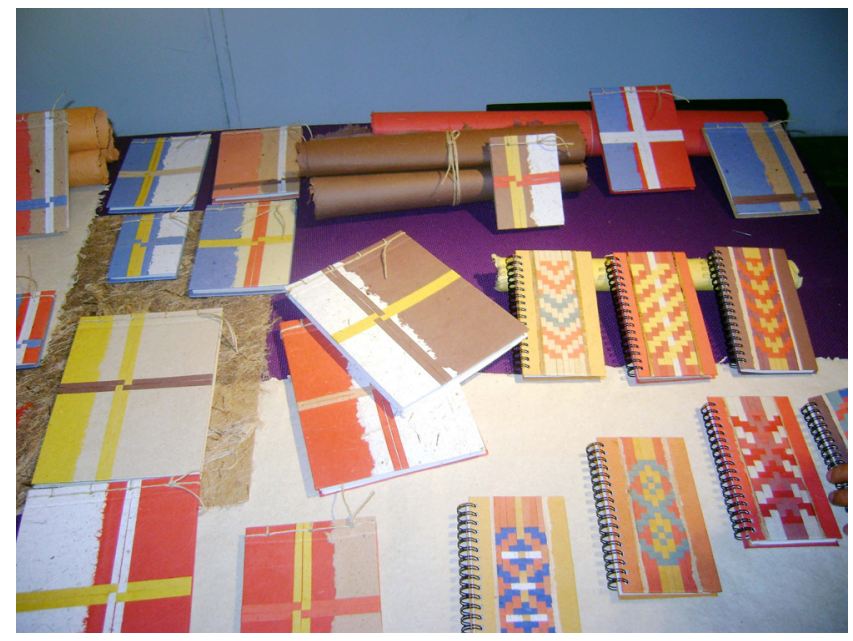

Figura 10: Agendas confeccionadas com trançado de papel reciclado Foto: Cristina Campos, 2009

fessores guarani Arnildo Werá e Eloir Werá Xondaro, a princípio, estranharam os objetos expostos no museu, pois concebiam que veriam "coisas de antigamente", que remetessem à história de seus ancestrais, como arcos, flechas e lanças; panelas produzidas com argila; pratos, colheres e canecas confeccionadas com sementes; colchão feito de folha de palmeira trançada; instrumentos, entre outros, que demandariam pesquisa para resgatá-los. Eloir Werá Xondaro argumenta:

Não sei, talvez eu possa estar errado. É algo importante que está sendo mostrado aqui, mas isso é da atualidade. Se a gente voltasse um pouco para a antiguidade, para a história dos nossos ancestrais, veríamos coisas diferentes aqui, uns instrumentos diferentes e até mesmo o artesanato um pouco mais diferente. Mas isso não quer dizer que isso aqui não é importante para a sociedade guarani hoje em dia. Isso aqui é uma exposição de grande importância para nós. Através dessa exposição talvez a sociedade dos brancos dê mais importância ao povo guarani. Não só aqui no Rio de Janeiro, mas em todo o território nacional. Isso é de muita importância para nós. São iniciativas assim que nos fortalecem. Os Guarani estão sendo um pouco esquecidos. Muito se fala de índio, mas pouco se fala dos Guarani. Existem várias etnias no Brasil. Principalmente os Guarani do Sul, de onde eu venho, é pouco falado, pouco lembrado. Os Guarani estão aqui no Rio de Janeiro, em São Paulo, no Sul, em Santa Catarina, na Argentina e no Paraguai. O povo guarani está vivo, sua cultura está viva, seus costumes estão vivos. Então, isso nos fortalece, não só fortalece como uma aldeia, mas como um todo, o povo no geral assim. Eu fico feliz pelos meus parentes terem conseguido esta oportunidade de estar mostrando um pouco das aldeias. E eu parabenizo esses guerreiros pela coragem também de estar expondo isso assim. Também fico muito feliz. Mas, o importante é mostrar a iniciativa, mostrar o suficiente para a sociedade conhecer um pouco da cultura guarani, mas isso é insuficiente.

Com relação ao acompanhamento de visitantes, Eloir Werá Xondaro entendeu que existe necessidade de um monitor guarani para explicar um pouco sobre os objetos e 
imagens apresentados, visto que as percepções e os entendimentos são diferentes. Uma imagem provoca interpretações próprias e no caso apresentado existe o desejo guarani de se mostrar a partir de seu olhar, ainda que traduzidos pelos juruás.

Ver seus trabalhos na exposição significou para o escultor e cineasta Miguel Rogério Vera Mirim reconhecimento e valorização de sua arte/cultura. Suas peças e documentários apresentados no museu garantem contínua visibilidade. "Fico feliz! Um trabalho que as pessoas reconhecem. Fico feliz! Mostrar meu trabalho para os não índios. Por isso, eu fiz meu trabalho; daqui a cinco ou seis anos ele estará aqui".

\section{A ALDEIA COMO ESPAÇO CULTURAL E ETNOTURÍSTICO}

O conceito de museu tem sido discutido pelos índios que não aceitam mais passivamente que os museus construídos por não índios tenham o monopólio do discurso histórico que lhes diz respeito. Querem deixar de ser apenas um objeto musealizável e ser também - eles próprios - agentes organizadores de sua memória. A existência de museus tribais pode não apenas enriquecer os museus etnográficos, mas contribuir para a formação dos grandes museus nacionais (FREIRE, 1999).

Reproduzir a imagem, espelhar, revelar, meditar e repercutir são alguns dos procedimentos adotados por alguns índios que realizam projetos incluindo a produção de documentários sobre seu modo de ser e agir. Evidenciando a identidade como um processo dinâmico, a memória adquire nova dimensão quando torna possível o confronto de imagens do presente com a lembrança de suas práticas. As experiências de representação de saberes e de práticas ditas "tradicionais" empreendidas por comunidades indígenas evidenciam, segundo Dominique Gallois (2006), a transformação dos modos de produção e reprodução de saberes, assim como das modalidades de intercâmbio. Como pano de fundo, a construção de coletivos étnicos, sujeitos de direitos de "propriedade", permite discutir o terreno em que as proposições relativas à salvaguarda de patrimônios indígenas se assentam.

Nessa via de compreensão, a vida dos objetos deriva diretamente do universo imaginativo que eles são capazes de invocar e condensar. O sentido assume outro corpo conforme o contexto no qual o objeto se insere, quando sujeitos/objetos entram no circuito comercial interétnico, quando se tornam emblemas de identidade étnica, quando se tornam peças de museus ou "obras de arte".

Os Guarani Mbyá da Aldeia Tekoa Mbo'yty ${ }^{3}$ têm construído modos próprios de preservação, divulgação, reconhecimento e valorização de seu patrimônio material e imaterial. Idealizam a aldeia como um lugar de memória viva, quando permitem aos "estrangeiros" que visitam suas terras conhecer seu modo de viver, pensar e agir - assistindo a rituais, aprendendo a língua nativa, participando de oficinas, entre outros eventos programados por eles.

3 A Aldeia Tekoa Mbo'yty (Aldeia de Sementes) está assentada no Sambaqui Duna Pequena, em Camboinhas, bairro nobre situado na Região Oceânica do município de $\mathrm{Ni}$ terói. Criada em 2008, a área é considerada sagrada pelos Guarani, por abrigar fósseis e relíquias dos antepassados indígenas. São 63 índios falantes da língua tupi-guarani que, através da palavra cantada, falada e, atualmente, da palavra escrita, evocam a memória de seu povo. 


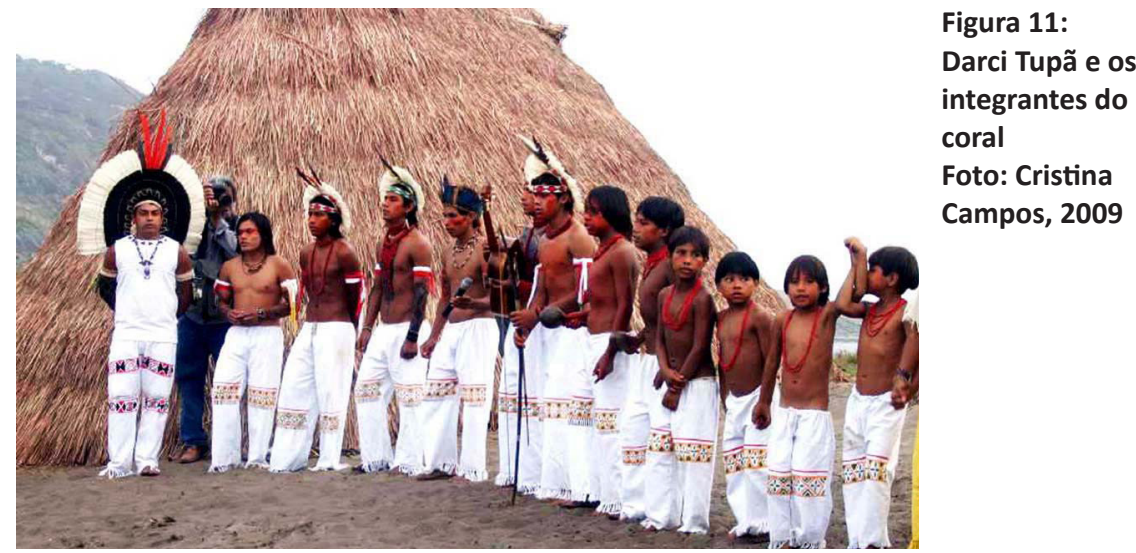

A localização da aldeia na urbe traz algumas reflexões sobre a situação recorrente em que se encontra - lócus de especulação imagética. Nesse sentido cabe ressaltar que o corpo da aldeia recebe constantemente a visita de pessoas com interesses diversos: fotógrafos em busca de uma imagem "aurática"; cineastas, repórteres

4 Em 2009 o prefeito de Maricá, Washington Quaquá, com interesse em abrigar os índios numa reserva situada no município e, com isso, aumentar o turismo na região, convidou os Guarani para construir sua aldeia em terra a ser demarcada como reserva indígena. Nessa reserva, projetaram uma "aldeia modeIo" com ocas para visitantes que desejam vivenciar os costumes guarani. Até o momento aguardam a demarcação da terra para realização do projeto. em busca de um tema que desperte o interesse dos espectadores; instituições educativas, fundações, museólogos em busca de material representativo da etnia indígena; representantes municipais interessados na criação de uma "aldeia modelo" como polo turístico. ${ }^{4}$

Desde abril de 2009, a comunidade indígena de Camboinhas tem apresentado para os juruás eventos que incluem atividades como competição de arco e flecha; oficina de pintura corporal; mostra de comida típica; apresentação de danças e do coral; construção de ocas; brincadeiras indígenas; exposição da arte guarani; além do ritual do batismo. Os eventos têm como objetivo difundir informações sobre seu modo de vida e as dificuldades que enfrentam atualmente, tentando conquistar o respeito por sua cultura, bem como o desenvolvimento sustentável da aldeia.

No mês de abril, em que se comemora o Dia do Índio, a aldeia se torna espaço pedagógico, recebendo a visita de alunos das escolas da cidade. Os Guarani cantam, dançam, brincam, contam suas histórias para os ouvintes, que levam para casa informações diferentes das apresentadas nos livros didáticos e alguma lembrança guarani - objetos produzidos por eles.

O semblante dos Guarani da Aldeia Tekoa Mbo'yty tem despertado nos fotógrafos grande interesse, fazendo com que o cacique Darci Tupã estabeleça algumas alianças. Cerca de 30 fotógrafos do grupo Friends, em agosto de 2009 - mês em que se realiza a purificação e o fortalecimento da terra e a evocação de boas energias para o povo guarani -, capturaram uma série de imagens do espaço físico, ritual e corporal da aldeia. Du- 


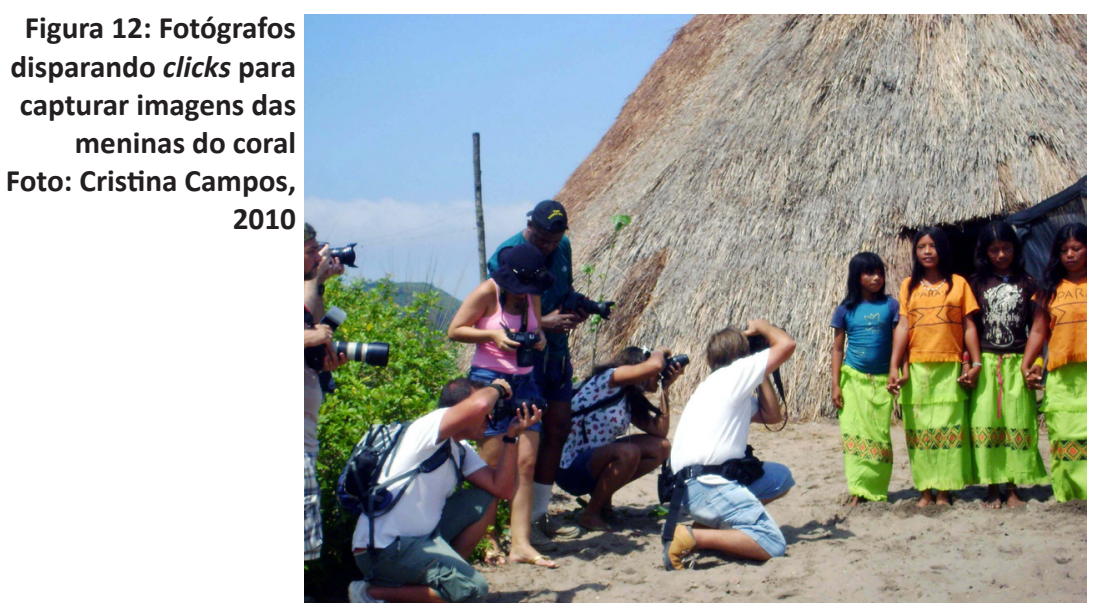

rante todo esse dia, os índios organizaram eventos para que os fotógrafos registrassem diferentes momentos, costumes, poses e para tal se vestiram com "roupas de festa": corpos pintados com grafismos guarani, roupas de saco com a barra desfiada e pintada com linhas e formas geométricas, cordões de miçangas ou sementes, brincos e cocares de pena de galinha ou pássaros (Figura 11). No final do dia, realizaram o ritual do batismo.

Antes do início da cerimônia o cacique Darci Tupã falou sobre a resistência de sua mãe - a pajé Lídia Para Yry Nhe'?]já, cujo nome revela sua ligação com o plano cosmológico: guardiã do espírito - quanto à entrada dos brancos na Casa de Reza e participação na cerimônia:

Desde o início eu falo para minha mãe que a gente tem que dar uma oportunidade às pessoas para conhecer nossa cultura, nossa aldeia, senão a gente fica muito isolado. E se a gente não abre a porta como é que vocês vão conhecer a gente? Um morador de Camboinhas, outro dia, falou que não gostava de índio porque tinha lido nos livros da escola que os índios comem carne de gente, são canibais. Depois de conhecer a gente viu que nós não somos aquilo que muita gente pensa. Então, é por isso que a gente abre nossas portas para vocês conhecerem a nossa cultura, para depois falarem para os seus familiares que não é isso que eles pensam, que índio é gente igual a todo mundo.

Após muita conversa, o argumento de que o conhecimento de seus costumes, através de relacionamento mais próximo com os brancos, traria possibilidade de respeito e valorização de suas crenças fez com que a pajé permitisse a participação dos "estrangeiros". Lídia Para Yry Nhe'?]j, no entanto, exigiu que os fotógrafos seguissem sua orientação quanto aos registros fotográficos, que excluía o momento da nominação das crianças - o "batizado", como o chamam os Guarani.

Os fotógrafos e as pessoas ${ }^{5}$ que receberiam o nome, enviado 5 Nesse dia, além de algumas crianças guarani, alguns brancos, eu entre eles, a convite do cacique e da pajé, receberam o nome indígena. por Nhanderu à pajé, e o coral se posicionaram para a realização da cerimônia: fotógrafos e espectadores na lateral, os batizandos na primeira fila em frente 


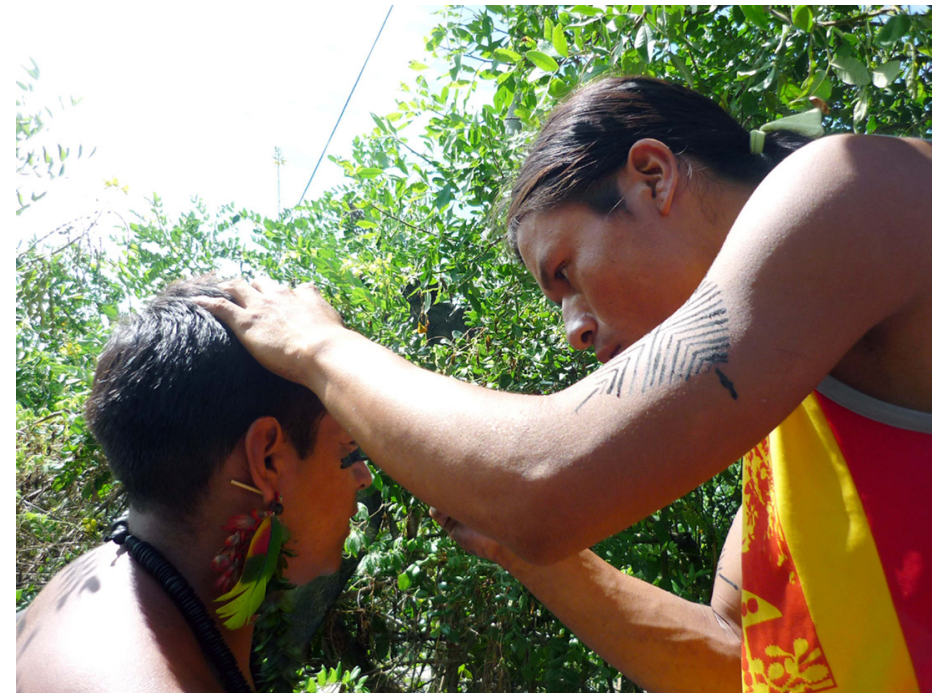

Figura 13:

Nivaldo

Karai Mirim

pintando o

cacique Darci

Tupã

Foto: Cristina

Campos, 2010

ao Ambai (instalação sagrada), os batizados antecessores na segunda fila, o coral na lateral esquerda do Ambai, as mulheres batendo a takuapú (taquara) no chão na lateral direita, e os homens circulando ao redor dos batizandos e batizados, baforando-lhes a cabeça com fumaça do petÿgua (cachimbo). A pajé inicia também sua circulação, até que em determinado momento sopra no ouvido do batizando seu nome. A cerimônia encerra com a fala do cacique que agradece a participação e a contribuição dos fotógrafos.

Os fotógrafos doaram para a aldeia alimentos, roupas, brinquedos, material escolar e de higiene pessoal, contribuições em dinheiro, além de um datashow para exibição das imagens registradas. As fotografias integraram uma exposição itinerante pelas universidades do Rio de Janeiro e Niterói. Segundo o fotógrafo Martinusso a mostra tem cunho jornalístico; no entanto, afirma que os Guarani "são muito fo-

6 Depoimento concedido à pesquisadora em dezembro de 2009, na mostra fotográfica realizada na Universidade Federal Fluminense (UFF), no município de Niterói. togênicos, resultando um material interessante e artístico"6. No lançamento da exposição na Universidade Federal Fluminense (UFF), a polêmica surgiu em torno da falta de identificação das pessoas fotografadas, bem como de um material informativo sobre a aldeia e o grupo indígena. Justificaram que a intenção do grupo é "ajudar" os indígenas e que tomariam as devidas providências nas próximas exposições.

Em 2010, no mês de janeiro, época em que todas as aldeias guarani mbyá realizam a festa do milho - Nimongarai, quando tudo se renova -, outro grupo de fotógrafos adentra o espaço da aldeia munido de suas máquinas. Dessa vez cerca de 60, do Clube do Rio Fotos, entre amadores e profissionais, disparam seus clicks sobre o corpo da aldeia (Figura 12). Maurício Basílio, um deles informou que o grupo se constituiu em 2003 no espaço virtual da Internet e que hoje utiliza um varal para expor suas fotos mensalmente no Centro do Rio de Janeiro. 


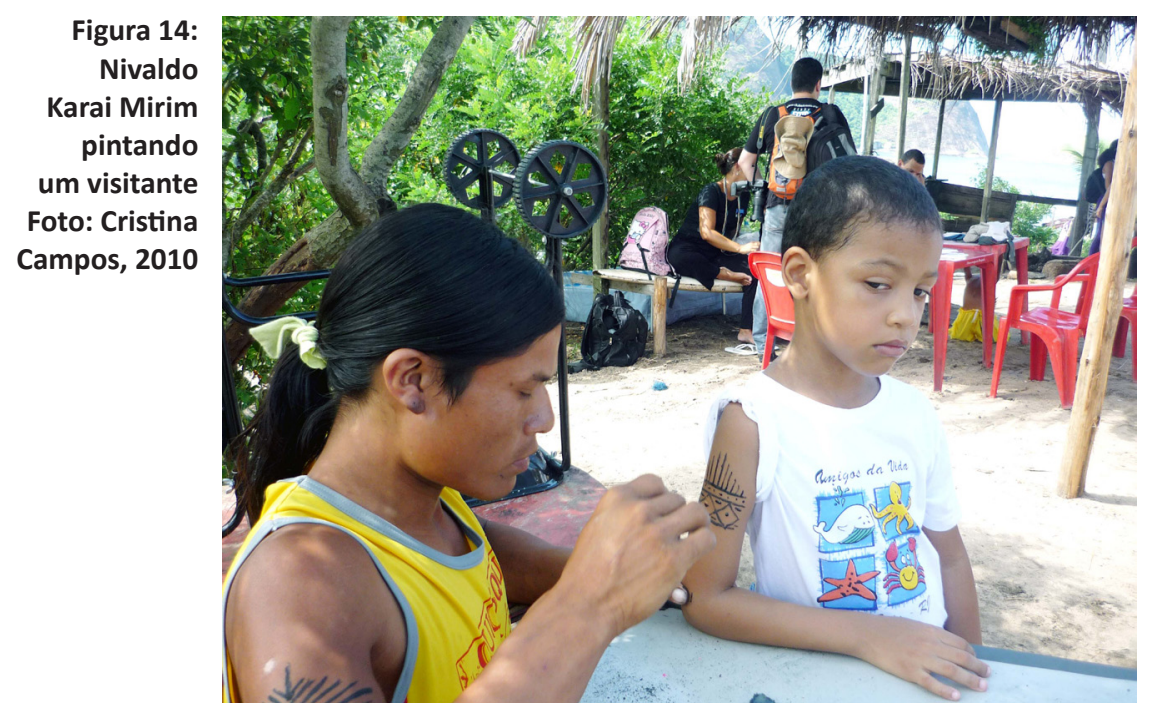

Procuramos fotografar lugares legais. A gente não vai expor a pobreza em si, apesar de estar aqui vendo isso tudo. Nosso intuito é ajudar, fazer projetos para ajudar essa comunidade, que é muito carente. $O$ sentido não é divulgar a pobreza deles, isso não dá certo. ${ }^{7}$

A declaração do fotógrafo mostra a relação estabelecida entre eles e a comunidade indígena: uma economia simbólica, cujo foco se concentra no interesse de cada ator social.

Na entrada, o local de venda/exposição da produção artística dos núcleos familiares da aldeia dividiu o espaço com a mostra fotográfica itinerante do Grupo Friends, já mencionada. Em destaque, a parede, suporte das fotografias, construída com o trançado de folhas de palmeira despertou interesse de alguns olhares apurados - o trançado se entranha nas imagens e evoca a verve artística dos Guarani.

A pintura corporal (figuras 13 e 14) foi bastante explorada pelos visitantes que incansavelmente questionavam o significado do grafismo. Muitos foram esclarecidos, mas entre tantos um não obteve resposta, causando insatisfação da curiosa, que resmungou: "Isso que dá ser aculturado, não sabe o que quer dizer o desenho!" No entanto, as manifestações, realizadas durante o dia e a noite, serviram de material para organização de futuras exposições.

A aliança estabelecida com os fotógrafos pode ser considerada expertise $e^{8}$ do cacique Darci Tupã, uma vez que: já vivenciou inúmeras vezes situações desfavoráveis quando em contato com a sociedade dos brancos, situação que não deseja mais experimentar; os questionamentos levam à procura de respostas nos arquivos vivos

7 Depoimento concedido à pesquisadora em janeiro de 2010, na festa realizada na aldeia.

8 Palavra de origem francesa é aplicada as pessoas especialistas, que são peritas em um assunto. O fenômeno da expertise, segundo Tornatore (2007), se caracteriza por sua natureza altamente instável. Essa perícia é basicamente uma posição temporária assumida frente a uma situação de tensão. 
da aldeia, os mais velhos; e, por fim, as contribuições ofertadas por patrocinadores proporcionam o desenvolvimento necessário a uma comunidade que deseja viver num centro urbano.

\section{CONSIDERAÇÕES FINAIS}

O espaço de projeção da arte/cultura guarani, em interface com o espaço-tempo

9 Hélio Oiticica introduz o termo em 1960, com seu

PN1. Sua obra conquista dimensão ambiental capaz de impregnar-se do mundo em estreito diálogo com o espectador. dos juruás, seja ele no museu ou na aldeia, se configura em paisagem "penetrável", 9 estrutura fixa a ser desvendada pela incursão do indivíduo, ambiente a ser atravessado pelo espectador. Eternamente móvel, transformável, que se estrutura pelo ato do espectador, e estático, que é também transformável a seu modo, dependendo do ambiente em que esteja participando como estrutura, o espaço de exposição muda, "de nada significa mais 'expor' tais peças (...), mas sim a criação de espaços estruturados, livres ao mesmo tempo à participação e invenção criativa do espectador". (OITICICA, 1986: 79). Mais que ver, é preciso vivenciar, penetrar o passeio do sentido mbyá.

A imagem-corpo guarani vestida de penas de animais, pintada com tintas e envolvida com colares obtidos de elementos da natureza talvez exerça nos brancos e nos índios um "fetichismo visual", resultado de "tramas tecidas por constantes trânsitos de significados que são interpretados contextualmente, refutando cada simplificação arquetípica ou homologante" (CANEVACCI, 2008); um fascínio simétrico. O desejo de cristalizar a imagem primitiva - em harmonia com a natureza - pode restituir, a nós brancos, a lentidão dos dias, um contato com a liberdade ou, ainda, fazer-nos reviver o desejo colonialista euro-ocidental de manter o índio catequizado, porém no esplendor de sua beleza nua a ser eternamente congelada e assim admirada. Para os índios, o fato de desejarem se olhar na imagem de homens-natureza, sendo, aliás, condição à exposição das lentes fotográficas, talvez seja fruto da necessidade de alimentar referência identitária calcada no "erotismo selvagem" que a própria imagem proporciona.

Sujeitos/objetos da cultura material e imaterial, textos, fotografias, instalações cenográficas, jogos interativos, elementos audiovisuais da produção artística guarani se apresentam em outro cenário que, com a organização de museólogos, antropólogos e participação dos próprios índios, tem contribuído para reforçar os sentimentos de pertencimento étnico e autoestima do grupo social envolvido. A arte/cultura guarani mbyá implica, portanto, a alteridade que assegura a igualdade. A alteridade é a condição imanente de categorização da experiência real e virtual, e, ao mesmo tempo, um vínculo necessário que dá ao corpo sentido e sustentação, uma ontologia relacional, uma circulação livre das diferenças. 


\section{REFERÊNCIAS BIBLIOGRÁFICAS}

ABREU, Regina. Patrimônios etnográficos e museus: uma visão antropológica. In DODEBEI, V.; ABREU, R. (orgs.). E o patrimônio? Rio de Janeiro: Contracapa/Programa de Pós-Graduação em Memória Social da Universidade Federal do Estado do Rio de Janeiro, 2008: 33-58.

CANEVACCI, Massimo. Antropologia da comunicação visual. Rio de Janeiro: DP\&A, 2001. Cultura e pensamento $12-$ A respeito dos novos fetichismos visuais. 10/03/2008. Disponível em: <http://www.culturaemercado.com.br/setor. $p h p$ ?setor=4\&pid=3822>. Acesso em: 10 de abril de 2010.

CHAGAS, Mario. Memória política e política de memória. In ABREU, R; CHAGAS, M. (orgs.). Memória e patrimônio: ensaios contemporâneos. 2a ed. Rio de Janeiro: Lamparina, 2009: 136-167.

FREIRE, José. Ribamar Bessa. Língua e literatura oral em Couto de Magalhães. In Cadernos de Resumos do IX Congresso da Assel. Rio de Janeiro: Assel, v. 1, 1999: 41-41.

GALLOIS, Dominique. A etnificação de bens culturais indígenas. Colóquio Guiana Ameríndia. História e Etnologia. Belém: NHII/USP, 2006. Disponível em: <http: //www.unb. br/ics/dan/geri/boletim/gallois_2006.pdf.>. Acesso em: 08 de nov 2009.

LEIBNIZ, Gottfried Wilhelm. La monadologie. Paris: Librairie Général Française, Édition critique établie par Émile Boutroux, 1991.

MENDES JÚNIOR, Rafael. Os animais são muito mais que algo somente bom para comer. Dissertação de Mestrado em Antrologia. Universidade Federal Fluminense, Brasil, 2009.

OITICICA, Hélio. Aspiro ao Grande Labirinto. Rio de Janeiro: Rocco, 1986.

PISSOLATO, Elizabeth. A duração da pessoa: mobilidade, parentesco e xamanismo mbyá. São Paulo: Unesp, 2007.

RIBEIRO, Leila Beatriz. Patrimônio visual: as imagens como artefatos culturais. In DODEBEI, Vera e ABREU, Regina (orgs.). E o patrimônio? Rio de Janeiro: Contracapa., 2008:. 59-72.

TIESSE, Anne-Marie. A criação cultural das identidades nacionais na Europa. Trad. Sérgio A. Souza. Disponível em: http://www.gtehc.pro.br/.../2-Anne-Marie\%20Thiesse-\%20 A\%20criacao\%20cultural\%20das\%20identidades\%20nacionais.html. Acesso em: 16 set de 2009.

TORNATORE, Jean-Louis. Qu'est ce qu'un ethnologue politisé? Expertise et engagement en socio-anthropologie de l'activité patrimoniale. Etnogra'hiques.org/n. 12, 2007. Disponível em http://www.tornatore.html. Acesso: 20 dez de 2009.

Cristina R. Campos é mestre em artes pelo PPGArtes/Uerj e doutoranda em memória social pela UniRio.

CAMPOS, Cristina R. Espaço de projeção do patrimônio artístico e cultural Guarany Mbyá. 
